\title{
Providing warmth for preterm babies by a heated, water filled mattress
}

\author{
I SARMAN AND R TUNELL \\ Department of Paediatrics, Huddinge Hospital, Karolinska Institute, Huddinge, Sweden
}

SUMMARY Seventeen healthy preterm babies had extra warmth provided in their cots by thermocontrolled, heated, water filled mattresses. As controls 17 babies of the same weight were nursed in air heated incubators. Both groups were studied for three weeks. No differences were found in minimal oxygen consumption (measured by indirect calorimetry), rectal and mean skin temperatures, or in daily weight gain. The babies were kept just as warm on the heated, water filled mattresses as in air heated incubators but the mattresses had the advantage of giving the mothers easy access to their babies.

Air heated incubators and thermocontrolled radiant heaters are most often used to warm preterm babies in modern neonatal care units. Both techniques are complex, expensive, and require a continuous electrical supply. These techniques are, therefore, not suitable for use in most developing countries. After recommendations from UNICEF, and a commission of the World Health Organisation, a heated, water filled mattress was developed as an alternative. ${ }^{1}$

The present study was set up to compare the long term thermal effects of nursing healthy preterm infants in cots with the heated, water filled mattresses, with those of a control group of infants treated in single walled, air heated incubators.

\section{Patients and methods}

Each infant was cared for after birth during a stabilisation period in an air heated incubator. Thirty four premature or low birth weight, or both, infants were included in the investigation when they had reached a weight of 1400 to $1999 \mathrm{~g}$. Infants who were free from infections, cardiopulmonary diseases, and gross malformations were studied as soon as they no longer needed supplementary oxygen. Informed consent from one or both parents was obtained.

The 34 babies were randomly allocated to either a study group who were nursed in cots on heated, water filled mattresses $(n=17)$ or to a control group who were maintained in air heated incubators $(n=17)$. The study period ran from the day of randomisation to the day when the baby moved to an ordinary cot. This occurred for babies on the mattresses when the mattress temperature was $36^{\circ} \mathrm{C}$, and for the incubator group when the air temperature in the incubator was $30^{\circ} \mathrm{C}$, and the babies had normal, stable body temperatures.

The gestational age of all but two infants was determined from the early (16 to 17 weeks) ultrasonographic estimate of the fetal biparietal skull diameter. In two infants ultrasonographic examinations had not been performed and therefore postnatal maturity evaluation by Finnström's method was used. ${ }^{2}$

There were no significant differences between the groups in the mean age of the mothers, parity, or the gestational age. In both groups there were large proportions of caesarean sections-seven in the mattress group and 12 in the incubator group; in both groups the main indications had been intrauterine growth retardation, or maternal toxaemia, or both (table 1). Four infants in the study group and six in the control group were classified as small for gestational age (below two standard deviations of birth weight, according to the Swedish national growth chart). ${ }^{3}$

There was no significant difference between the mean (SEM) stabilisation periods after birth in the two groups (11 (2) days (range 2-28) in the study group and 15 (4) days (range 3-55) in the control group). Five infants in each group were treated with supplementary oxygen for mild respiratory distress; all recovered without complications. Eleven babies in the study group and 13 in the control group needed phototherapy, but none received an exchange blood transfusion. All the mothers but one in each 
group produced enough breast milk to feed their infants.

There was no significant difference between the mean (SEM) body weights of the infants in the study group and the control group ((SEM) 1595 (35) $\mathrm{g}$ (range 1400-1820) and 1569 (31) g (range 14301845)) at the start of the study period.

Table 1 Characteristics of the study groups at birth

\begin{tabular}{|c|c|c|c|}
\hline & $\begin{array}{l}\text { Heated, } \\
\text { water filled } \\
\text { mattress } \\
(n=17)\end{array}$ & $\begin{array}{l}\text { Incubator } \\
(n=17)\end{array}$ & $p$ Value \\
\hline \multicolumn{4}{|l|}{ Mean (SEM) birth } \\
\hline Range & $1130-1900$ & $904-1980$ & 100 \\
\hline $\begin{array}{l}\text { Mean (SEM) length } \\
\text { at birth }(\mathrm{cm})\end{array}$ & $41.9(0.5)$ & $40 \cdot 1(0 \cdot 8)$ & $\leqslant 0.005$ \\
\hline $\begin{array}{l}\text { Mean (SEM) head } \\
\text { circumference }(\mathrm{cm})\end{array}$ & $29.0(0.4)$ & $28.4(0.6)$ & NS \\
\hline $\begin{array}{l}\text { Mean (SEM) } \\
\text { gestational age }\end{array}$ & & & \\
\hline (weeks) & $32(0 \cdot 5)$ & $32(0 \cdot 6)$ & NS \\
\hline Range & $29-35$ & $28-35$ & \\
\hline $\begin{array}{l}\text { No of babies small for } \\
\text { gestational age }\end{array}$ & 4 & 6 & \\
\hline
\end{tabular}

The heated, water filled mattress (Kanthal Medical Heating AB, Stockholm, Sweden) (fig 1) is a polyvinylchloride bag filled with $10 \mathrm{l}$ water. The mattress is heated by a pad with heating foil covered by plastic and containing five built in thermistors. Two of the thermistors regulate the temperature, two are safety controls to avoid overheating, and one records the temperature of the mattress on a digital display. The heating pad is supplied with $24 \mathrm{~V}$ AC with a maximum effect of $50 \mathrm{~W}$. The temperature can be regulated in seven steps between $35^{\circ}$ and $38^{\circ} \mathrm{C}$, and overheating as well as underheating alarms are built in. When the electricity supply is interrupted the alarm goes off. The mattress is placed in the crib. Each infant is dressed in a cotton shirt, a nappy and a cotton dress. If a baby weighs less than $1500 \mathrm{~g}$ he wears a cotton cap. Each infant is placed on the mattress and covered with a blanket.

The incubator used in the study was a single walled, manually controlled, air heated incubator AGA MK41 (AGA AB, Lidingö, Sweden). The infants in the incubators wore only nappies. Temperature adjustments of the mattresses and the incubators were made by the nursing staff after the

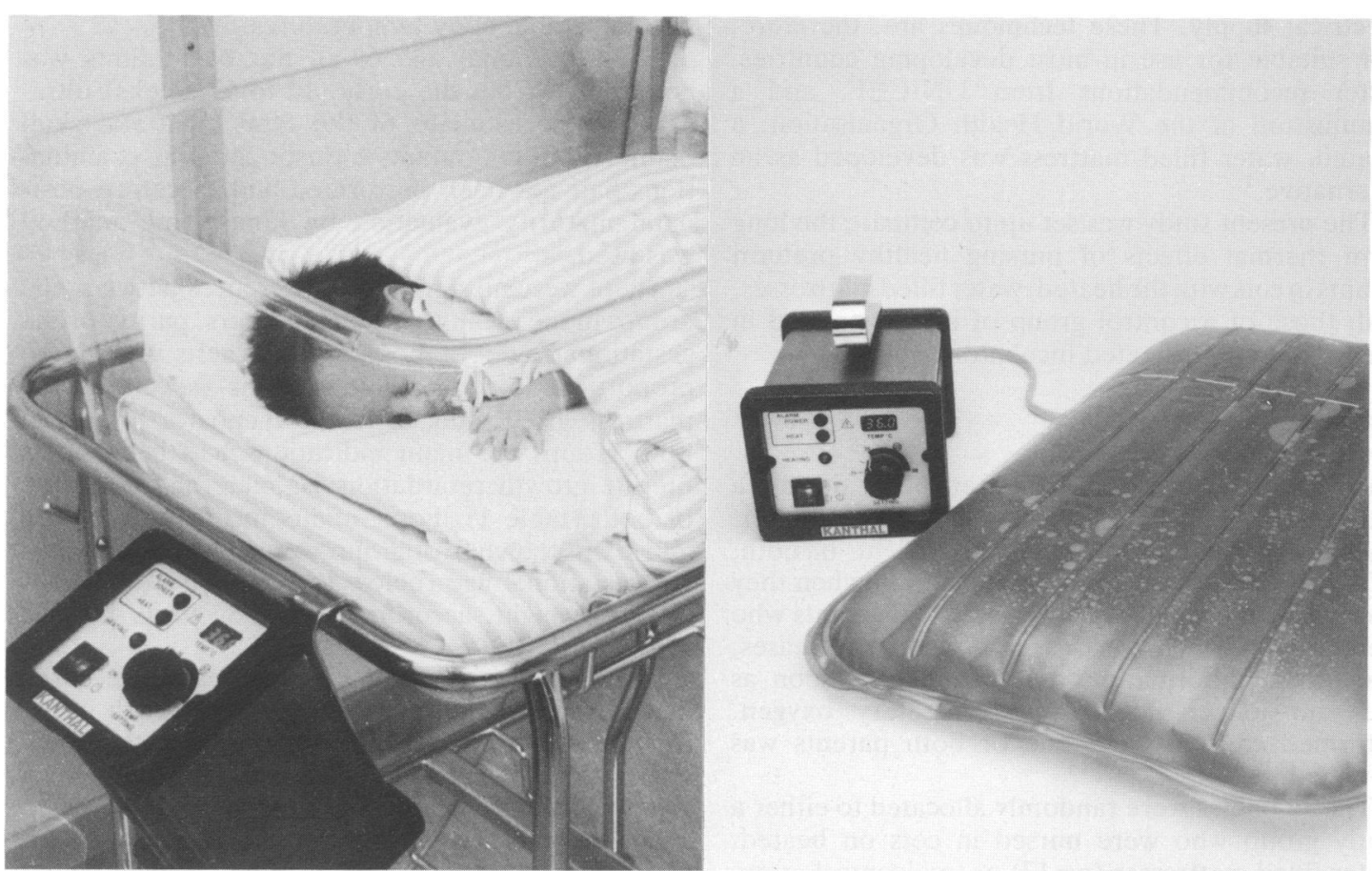

Fig 1 Heated, water filled mattress. The polyvinylchloride bag is filled with $10 \mathrm{l}$ water. The temperature control unit is connected to the heating pad which is placed under the bag (right). Baby of $1500 \mathrm{~g}$ on the mattress, in a crib in the neonatal intensive care unit (left). 
rectal temperatures of the babies had been recorded four times daily with a mercury thermometer. A rectal temperature between $36.5^{\circ} \mathrm{C}$ to $37.5^{\circ} \mathrm{C}$ was maintained. ${ }^{4}$ The nursery's ambient temperature was maintained at about $25^{\circ} \mathrm{C}$ (mean (SEM) $\left.24.8(0.02)^{\circ} \mathrm{C}\right)$.

All infants were fed breast milk by nasogastric tube, either with their mother's expressed milk or with a supplement of banked human milk. Feeding volumes were provided according to the recommendations of the European Society of Paediatric Gastroenterology and Nutrition-160 to $220 \mathrm{ml}$ breast milk/kg body weight day after the first postnatal week. ${ }^{56}$

The weight was recorded daily to the nearest $5 \mathrm{~g}$ and the rate of weight gain was calculated as $\mathrm{g} / \mathrm{kg}$ body weight/day, and averaged for seven days. Skinfold thickness was measured once a week at five sites (biceps, triceps, subscapularis, flank, and quadriceps), using Harpenden calipers, and the mean skinfold thickness was calculated. ${ }^{7}$ Once a week, determinations of heat production and more exact temperature measurements were performed.

The infant's resting oxygen consumption as an indicator of heat production was determined by indirect calorimetry. A continuous open flow circuit method was used with a Plexiglas hood placed over the infant's head. For infants nursed on the mattress the air and wall temperatures of the hood were kept between $24^{\circ} \mathrm{C}$ and $25^{\circ} \mathrm{C}$ by circulating water through the inner wall of the hood. The flow of fresh air through the hood was measured with a Fleish pneumotacograph and regulated to achieve a carbon dioxide concentration of $0.5 \%$ in the diluted expired air. This resulted in an airflow of 1.0-2.5 $1 /$ minute . The pneumotacograph was calibrated against a Tissot spirometer. Air samples from the diluted expired air were drawn every fifth minute during the investigation period. The gas analyses were carried out with a paramagnetic oxygen analyser (Magnos 2T, Switzerland) and an infrared carbon dioxide analyser (Uras 3G, Switzerland). All the volumes were corrected for standard temperature and pressure, dry and computed on line. ${ }^{89}$ The system was calibrated before and after every investigation with ambient air and a known gas mixture (diluted air with $8 \%$ nitrogen and $2 \%$ carbon dioxide) using a mixing pump (H Vösthoff OHG, Type Eg725 Bochum, West Germany).

The infant's state of activity was recorded using Brück's method during the heat production measurements. ${ }^{10}$ Minimal oxygen consumption was calculated from the values obtained when the baby had been quietly sleeping during at least four periods of five minutes each. Simultaneously temperatures from the following sites were recorded every five minutes, using thermocouples (Exacon 9000, Denmark): rectum (5 $\mathrm{cm}$ above the anus); skin (five sitesforehead, anterior abdomen, back, thigh, and foot); incubator air (centrally $10 \mathrm{~cm}$ above the infant's body); water in the heated mattress; and room air close to the baby.

The mean skin temperature was then calculated using weighting factors. ${ }^{11}$ The accuracy of the thermocouples was checked several times against a $25 \mathrm{~cm}$ long mercury thermometer in a water bath at $20^{\circ}$ and $40^{\circ} \mathrm{C}$, and no deviation was found. The incubator air and the mattress water temperature were adjusted to the same temperature as that previously used.

The mean (SEM) and range were calculated to describe the group characteristics; for the quantitative differences between the groups the unpaired $t$ test (one tail) was used, and for the frequency differences the $\chi^{2}$ analysis, was used. A p value of $\leqslant 0.05$ was accepted as significant.

\section{Results}

The duration of the study varied between infants because of differences in maturation and body weight at the start of the study period. Seventeen, 16 , and nine infants in the study group, and 17,16 , and six infants in the control group were studied during one, two, and three weeks, respectively.

The mean weight gain ( $\mathrm{g} / \mathrm{kg}$ body weight/day) was slightly but not significantly higher, during all three of the study weeks in the group treated on the heated, water filled mattress, being $10.8(2.0)$ and $8.0(3.0)$ during week one, $15.0(0.6)$ and $14.0(0.6)$ during week two, and $15.5(1.0)$ and $13.4(1.5)$ during week three.

The mean breast milk feeding volume $(\mathrm{ml} / \mathrm{kg}$ body weight/day) showed a slight but not significant difference during the first and third study weeks, being $167(4.1)$ and $168(6.5)$ during week one, $180(4 \cdot 1)$ and $182(2 \cdot 8)$ during week two, and $178(3 \cdot 4)$ and $184(3.3)$ during week three. There were no significant differences in the mean skinfold thickness measurements during the study period, with an average gain of $0.4 \mathrm{~mm} /$ week for both groups.

Breast feeding was actively encouraged, but the number of mothers who were able to maintain it differed significantly between the groups. At discharge, 11 of 17 babies in the study group were fed only their own mother's breast milk, compared with five of 17 in the control group ( $p \leqslant 0.05)$. There was no difference in the duration of feeding by nasogastric tube between the two groups.

The results of oxygen consumption are given in table 2. They are given both as the minimal and the average values during the three hour measurement 
Table 2 Mean (SEM) oxygen consumption (ml/kg/minute) in the two groups during the study period

\begin{tabular}{|c|c|c|c|c|c|c|c|}
\hline \multirow[t]{2}{*}{ Week } & \multicolumn{3}{|c|}{ Heated, water filled mattress } & \multicolumn{3}{|c|}{ Incubator } & \multirow[t]{2}{*}{ p Value } \\
\hline & $\begin{array}{l}\text { No of } \\
\text { babies }\end{array}$ & $\begin{array}{l}\text { Minimal } \\
\text { consumption }\end{array}$ & $\begin{array}{l}\text { Average } \\
\text { consumption }\end{array}$ & $\begin{array}{l}\text { No of } \\
\text { babies }\end{array}$ & $\begin{array}{l}\text { Minimal } \\
\text { consumption }\end{array}$ & $\begin{array}{l}\text { Average } \\
\text { consumption }\end{array}$ & \\
\hline 1 & 17 & $5.9(0 \cdot 2)$ & $6.4(0.2)$ & 17 & $6 \cdot 0(0 \cdot 1)$ & $6.5(0.2)$ & NS \\
\hline 2 & 16 & $6.9(0 \cdot 2)$ & $7.6(0.3)$ & 16 & $6.8(0.2)$ & $7.6(0.3)$ & NS \\
\hline 3 & 9 & $7 \cdot 6(0 \cdot 1)$ & $8.0(0 \cdot 1)$ & 6 & $6 \cdot 8(0 \cdot 2)$ & $7 \cdot 3(0 \cdot 1)$ & $\leqslant 0.05$ \\
\hline
\end{tabular}

period. The minimal oxygen consumption periods occurred approximately two hours after the last meal. No significant difference was found in the minimal and average oxygen consumption during the first two weeks between the two groups. In the third study week, a significantly higher oxygen consumption was observed among babies in the study group $(\mathrm{p} \leqslant 0 \cdot 05)$.

The results of the temperature measurements are shown in fig 2 . There were no significant differences in the rectal or mean skin temperatures between the
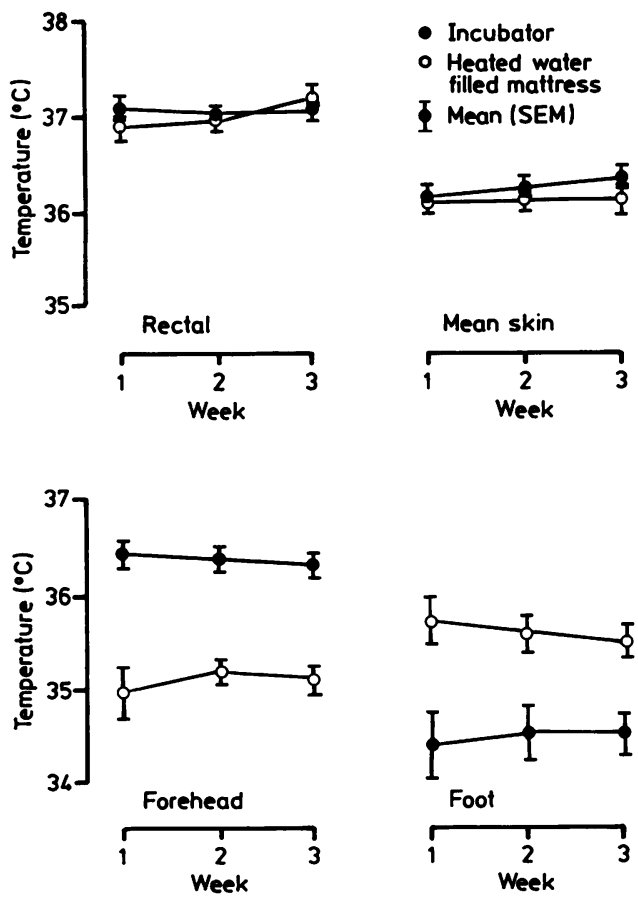

Fig 2 Changes in rectal, mean skin, forehead, and foot temperatures of babies treated on heated, water filled mattresses and in incubators during the three weeks of the study. During week 1 there were 17 babies in each group, during week 2 there were 16, and during week 3 there were nine and six, respectively; ${ }^{*} p<0.001$. groups, but the temperatures on the forehead and foot differed significantly. The mean forehead temperature of the infants in the study group was $1.5^{\circ} \mathrm{C}$ lower than that of the infants in the incubator group $(p \leqslant 0.001)$. On the other hand, the peripheral skin temperature, measured as the foot temperature, was $1.5^{\circ} \mathrm{C}$ higher in the study group than in the incubator group over the same period $(p \leqslant 0 \cdot 001)$.

The water temperature of the mattress differed from the air temperature in the incubator. The water temperature was close to $36 \cdot 5^{\circ} \mathrm{C}$, with small variation among infants during the three study weeks. On the other hand, the air temperature of the incubator started at $33.5^{\circ} \mathrm{C}$ and decreased by $0.7^{\circ}-0.8^{\circ} \mathrm{C}$ during the study period.

\section{Discussion}

The metabolic response of babies nursed in cots was studied in 1970 by Hey and O'Connell, who placed a warming element under an ordinary mattress. The oxygen consumption of 10 babies born at full term weighing 2000 to $3000 \mathrm{~g}$ decreased by $22 \%$ compared with the heat production recorded in unwarmed babies nursed in cots in an environment of $20^{\circ} \mathrm{C}^{12}$ The heat production of preterm babies in a cot with a heated, water filled mattress as heat source has not, to our knowledge, been reported. The mattress has several advantages over an ordinary heated mattress, including a high heat capacity, effective heat conduction, and a soft surface.

Our results indicate that the heat received from a heated, water filled mattress is equivalent to that from a conventional incubator. No difference was found in the minimal oxygen consumption, mean skin and body temperatures, and weekly weight gain. Our figures of minimal oxygen consumption in infants on a heated, water filled mattress confirm previous reports about infants in metabolic chambers or incubators. ${ }^{13} 14$

Cot nursing entails exposing the infant's face to the temperature of the ambient room air which, in most nurseries and neonatal wards, varies between $20^{\circ} \mathrm{C}$ and $25^{\circ} \mathrm{C}$. Mestyan et al reported that acute cooling of the faces of preterm babies causes a rapid 
increase in oxygen consumption. ${ }^{15}$ These results were not confirmed in our long term investigation. The baby nursed in a cot seems to adapt to the actual thermal conditions when treated continuously on the heated, water filled mattress, and does not increase its oxygen consumption although part of its face is cooled.

One specific advantage of this treatment is that it gives the mother easy access to her child and thus strengthens the early mother infant bonding. This may partly explain the significant increase in breast milk production on discharge from the hospital in the study group.

We conclude that the use of a heated, water filled mattress in a cot seems to be a simple, cheap, effective, and acceptable method of providing heat to healthy preterm babies who do not need intensive care in an incubator. This product can thus be an alternative to the incubator in both developing and developed countries.

This project was supported by a grant from the Swedish Medical Research Council (No 19X-06963-01). We thank Professor John Wahren in the department of physiology, for providing laboratory facilities for the calorimetry investigations.

\section{References}

1 Tunell R, Sarman I. The water-filled heated mattress. An alternative to incubator care in developed and developing countries? Neonatal physiological measurements. London: Butterworth, 1986;419-23.

${ }^{2}$ Finnström $O$. Studies on maturity in newborn infants. II. External characteristics. Acta Paediatr Scand 1972;61:24-32.
${ }^{3}$ Karlberg P, Fryer J, Ericson A, Niklasson A. Analysis of the size at birth by gestational age. Acta Paediatr Scand 1985;319 (suppl):26-34.

${ }^{4}$ Hey EN, Katz G. The optimum thermal environment for naked babies. Arch Dis Child 1970;45:328-34.

5 American Academy of Pediatrics Committee on Nutrition. Nutritional needs of low birth weight infants. Pediatrics 1985;75: 976-86.

6 ESPGAN Committee on the nutrition of preterm infants. Acta Paediat Scand 1987;336(suppl):4-5.

${ }^{7}$ McGowan A, Jordan M, MacGregor J. Skinfold thickness in neonates. Biol Neonate 1975;25:66-84.

8 Jequier E. Long-term measurement of energy expenditure in man: direct or indirect calorimetry? Recent advances in obesity research III. Proceedings of the 3rd International Congress on Obesity. London: John Libbey, 1981;130-5.

${ }^{9}$ Lister G, Hoffman JI, Rudolph AM. Oxygen uptake in infants and children: a simple method of measurement. Pediatrics 1974;53:656-61.

10 Brück $K$. Temperature regulation in the newborn infant. Biologia Neonatorum 1961;3:65-119.

11 Klein AD, Scammon RE. The regional growth in surface area of the human body in prenatal life. Proc Soc Exp Biol Med 1930;27:463-6.

12 Hey EN, O'Connell B. Oxygen consumption and heat balance in the cot-nursed baby. Arch Dis Child 1970;45:335-43.

13 Scopes JW, Ahmed I. Minimal rates of oxygen consumption in sick and premature infants. Arch Dis Child 1966;41:407-16.

14 Sinclair J, Scopes J, Silverman W. Metabolic reference standards for the neonate. Pediatrics 1967;39:724-32.

15 Mestyan J, Jarai I, Bata G, Fekete M. The significance of facial skin temperature in the chemical heat regulation of premature infants. Biol Neonate 1964;7:243-54.

Correspondence and requests for reprints to Dr Sarman or Dr Tunell, Department of Paediatrics, B-59 Huddinge Hospital, S-141 86 Huddinge, Sweden.

Accepted 18 July 1988 